\title{
Las nuevas tecnologías y el arte interactivo en la ciudad, como medios de elevación de la consciencia colectiva
}

\section{New technologies and interactive art in the city, as means of raising collective consciousness}

\author{
BELÉN LEÓN DEL RÍO \\ Profesora Contratada Doctora del departamento de Escultura e Historia de las Artes Plásticas \\ Facultad de Bellas Artes Santa Isabel de Hungría. Universidad de Sevilla (España) \\ belenleon@us.es
}

Recibido: 09/03/2017

Aceptado: 23/09/2017

\begin{abstract}
Resumen
El arte y las nuevas tecnologías estarían investigando nuevas vías de comunicación entre los individuos y el entorno, utilizando para ello los últimos avances materiales, empleando otros medios de información que empiezan a ser traducidos en el arte público de importantes ciudades de todo el mundo. Las grandes urbes se convierten así en elementos transformadores de nuestra consciencia, donde el arte digital en el espacio público, las fachadas mediáticas y el arte interactivo de las ciudades, serían una manifestación de cómo los creadores actuales estarían intentando a través de estos medios ligados a la configuración del espacio urbano, que el viandante llegue a alcanzar nuevos estados de consciencia, produciéndose una integración entre su campo vibratorio externo y su campo interior.
\end{abstract}

Palabras clave

Luz, interacción, consciencia, comunicación, arte. 


\begin{abstract}
Art and new technologies would be investigating new ways of communication between individuals and the environment, using the latest material advances, using other means of information that are beginning to be translated into the public art of important cities around the world. The big cities thus become transforming elements of our consciousness, where digital art in the public space, the media facades and the interactive art of the cities, would be a manifestation of how the present creators would be trying through these means linked Configuration of the urban space, that the passerby reaches new states of consciousness, producing an integration between its external vibrational field and its interior field.
\end{abstract}

\title{
Keywords
}

Light, interaction, consciousness, communication, art.

Referencia normalizada: LEÓN DEL RíO, BELÉN (2017): “Las nuevas tecnologías y el arte interactivo en la ciudad, como medios de elevación de la consciencia colectiva". Arte y Ciudad. Revista de Investigación, no 12 (octubre), págs. 35-58, Madrid. Grupo de Investigación Arte, Arquitectura y Comunicación en la Ciudad Contemporánea, Universidad Complutense de Madrid.

Sumario: 1. Las obras artísticas interactivas de la ciudad y su influencia en la consciencia colectiva de la sociedad. 2. La fusión entre arte y tecnología en las manifestaciones artísticas de la urbe. 3. La luz y la naturaleza como elemento de comunicación de masas en el arte interactivo de la ciudad. 4. Conclusiones. 5. Bibliografía.

\section{Las obras artísticas interactivas de la ciudad y su influencia en la cons- ciencia colectiva de la sociedad.}

En diversas ciudades se han instalado obras artísticas interactivas que se caracterizarían porque permiten la participación tangible de numerosos espectadores creando una comunicación que estaría por encima de las diferencias culturales entre países, estas obras captarían y procesarían señales procedentes del exterior, mostrando el resultado de forma perceptible, de manera que una vez percibidas producirían algún tipo de reacción interactiva, además las señales registradas ejercerían una influencia variable en el transcurso del proceso de la obra. 
Las ciudades se convertirían de este modo en protagonistas de la activación de procesos mentales que tendría lugar durante la observación de estas obras colocadas en las principales plazas y vías de las grande urbes. El artista mexicano Rafael Lozano Hemmer realizó un proyecto interactivo en el Zócalo de Ciudad de México, la tercera plaza más grande del mundo, donde participaron más de ochocientas mil personas de 89 países durante dos semanas. Este proyecto titulado Vectorial Elevation fue un encargo para dar la bienvenida al nuevo milenio, recibiendo numerosos premios como el Nica de oro del Prix Ars Electrónica del año 2000. Los participantes utilizaron una interfaz conectada a Internet donde había una lista de espera, para que cada persona, una vez llegado su turno, pudiera coreografiar sus dibujos sobre el cielo nocturno haciéndose visible en toda la ciudad. W. Lieser describe el funcionamiento de este proyecto:

El trabajo estaba compuesto por 18 reflectores móviles teledirigidos mediante robots, que eran visibles a una distancia de hasta quince kilómetros. Mediante una interfaz 3D en una página web de acceso libre, cada visitante podía fijar una coreografía para los reflectores móviles que entonces se ponían en funcionamiento. Cada seis segundos se transmitía una nueva coreografía a los reflectores móviles que era ejecutada y documentada. Los reflectores móviles estaban provistos de un navegador GPS. A cada participante se le facilitaba una página web personalizada en la que era posible encontrar imágenes, estadísticas y comentarios. (Lieser, 2010: 198-201)

Rafael Lozano Hemmer define este tipo de proyecto como "arquitectura relacional" designando estas actuaciones como "la actualización tecnológica de los edificios con memorias ajenas" (autor citado por Tribe, 1998: 62), es decir los transeúntes de la ciudad pueden dar nuevos significados a los edificios mediante herramientas tecnológicas. El artista mexicano crea así un arte extensible a un gran número de personas que no sólo son espectadores del proyecto, sino que se convierten en creadores, al poder ejecutar un nuevo diseño e incluir también en la página los textos no censurados de los participantes, las personas anónimas crearían así una nueva comunicación metafórica que tendría que ver con nuestro campo de consciencia colectivo.

K. Korotkov compararía las personas a una célula elemental que formaría parte de una estructura, de manera que sin estas células básicas la existencia y 
aparición de esta estructura no sería posible, e incluso si se produjera una destrucción de una "masa crítica de células" se destruiría la estructura, llegando así a la conclusión de que cada persona por el mero hecho de existir contribuiría a la existencia y el desarrollo de la humanidad. De igual manera cada individuo a través de su actividad creativa contribuiría al "campo de información global" explicando cómo las ideas que son desarrolladas y alimentadas bajo ciertas condiciones podrían formar "imágenes fantasma" estables a las que define igualmente como "imágenes forma" que empezarían a vivir de manera independiente de su creador:

Las ideas flotan en el aire; los mismos inventos y descubrimientos son realizados de forma independiente en diferentes partes del planeta. Podemos dar muchos ejemplos, el más importante de los cuales es el desarrollo de ideas espirituales de la humanidad (Korotkov, 2015: 207).

Este campo de información no incluiría solamente la estructura del campo de información de las imágenes forma, sino también las formas de información y comunicación corrientes, como las redes globales de comunicación, las redes de televisión, las redes de difusión de radio, los periódicos, los libros, los documentos profesionales especiales, los programas informáticos en los que incluye los juegos, las películas y vídeos, la comunicación oral y la correspondencia privada. Para K. Korotkov los campos estructurales de cada especie biológica que incluirían campos de información, surgirían por la actividad de estas especies y se desarrollarían a través de la evolución, junto con el desarrollo de estas especies. P. Teilhard de Chardin comparte las mismas ideas, describiendo nuestro futuro evolutivo:

Cada vez con mayor claridad, por todas las vías del conocimiento, nos descubrimos comprometidos solidariamente en un proceso (Cosmogénesis culminando en Antropogénesis) de donde depende oscuramente nuestra compleción o, si puede decirse, nuestra beatificación. La creciente evidencia de que la finalidad de cada uno de nosotros mismos (el ultra-ego de cada uno podría decirse) coincide con algún término común de la Evolución (con algún Super-ego común)... (Teilhard de Chardin, 1964: 350).

K. Korotkov señala cómo la mente del individuo podría influir directamente en nuestro entorno, siendo una cuestión que ha inquietado al hombre desde la antigüedad; para este autor nuestra consciencia tendría energía, considerando la conciencia como la "categoría ideal" y el "imperativo básico" junto con la 
materia y la información. En las ciudades la gente se comunicaría con cercanía entre sí, de manera que estaría constantemente intercambiando información, la vida de los individuos, su actividad diaria, estaría sincronizada y subordinada a un solo ritmo que no sólo tendría que ver con un intercambio de información que depende de conversaciones, periódicos, radio o televisión, sino que habría otro medio de información de naturaleza física a la que define como "campo de la conciencia colectiva". Existiendo campos de los diferentes sistemas y órganos del cuerpo humano que estarían sincronizados en su actividad:

Esto conduce a que formen un campo total con interferencia o, en otras palabras, un campo global con propiedades de interferencia holográficas. La idea de la coherencia del campo electromagnético del cuerpo se está desarrollando activamente en la biofísica moderna, por ejemplo, en Alemania, por el equipo de F. A. Popp, en Italia por Del Giudici y G. Vitiello, y en muchas otras universidades y centros de investigación. La interferencia o campo holográfico tiene propiedades muy interesantes; lleva información sobre el objeto que lo creó en cada una de sus partículas. Esto significa que si dicho campo se graba en un holograma, cuando se rompe la placa holográfica, cada fragmento contendrá información sobre todo el objeto. ¿No es igual que el espejo mágico de los cuentos de hadas de Andersen? (Korotkov, 2015: 191).

Para K. Korotkov no sólo existiría la idea del campo de un organismo individual sino también de un campo colectivo, desde el nivel de la familia, la nación, la denominación religiosa hasta llegar al nivel de humanidad:

En las urbes, la tensión del campo de información es en particular alta y afecta a las actividades intelectuales de las personas que están en este campo. El mismo proceso limita el desarrollo de los pueblos que viven como grupos familiares: en el curso de la existencia, no forman grupos suficientemente grades y estables como para producir un complejo campo de conciencia (Korotkov, 2015: 206).

En este mismo sentido C. G. Jung señala cómo en la medida en que la raza, el clan y la familia, tienen diferenciaciones correspondientes, habría también una psique colectiva limitada respectivamente a la raza, el clan y la familia, sobre el nivel de la psique colectiva universal (Jung, 1993a: 182). De esta forma se podría explicar que el inconsciente de pueblos y razas de distintos lugares presentaran coincidencias entre las formas y temas de los mitos autóctonos: 
La semejanza universal de los cerebros da por resultado una posibilidad universal de funcionamiento mental semejante. Esta función es la psique colectiva, que se divide en espíritu colectivo y alma colectiva (Jung, 1993a: 182).

Joseph Beuys concebía su actividad artística como un "programa educativo de gran alcance" encaminado a la libertad, donde los medios de comunicación serían un vehículo de difusión de su concepto de "escultura social", cuyo objetivo era propagar la idea de un "arte extenso" que sobrepasara el mero fin estético y englobara todos los ámbitos de la vida. Este artista partía de la premisa de que cualquiera podía crear un medio de comunicación o convertirse en artista. Esta forma de concebir el arte habría desembocado, en nuestros días, en las nuevas expresiones artísticas interactivas de las ciudades, cuya característica sería no estar predeterminada ni en lo que se refiere a su aspecto ni en su desarrollo, ofreciendo al espectador la libertad de un margen de maniobra para posibles evoluciones. El arte interactivo de la ciudad hace que el viandante se relacione con la obra de manera casual, produciéndose entre ambos una interacción que puede servir para romper con nuestras barreras habituales de comunicación entre las personas.

El habitante de la ciudad se convierte así, en un espectador activo, participando inconscientemente de una puesta en escena que atrae sus sentidos y que le sacaría de su tedio habitual poniendo en movimiento su subjetividad. Ejemplo de ello sería Body Movies realizada en 2002 por Rafael Lozano Hemmer, en una gran plaza situada en el casco antiguo de la ciudad de Linz. Para ello utilizó unos potentes reflectores que iluminaban un gigantesco lienzo que había sido montado sobre una grada:

Los reflectores estaban instalados sobre el suelo, a cierta distancia de la pantalla, de manera que proyectaban sobre ella las siluetas de los transeúntes. En las sombras que se reflejaban en el brillante y blanco lienzo las personas podían descubrir nuevas visiones de sí mismos o de los otros. Este efecto era causado mediante la proyección de una película sobre el mismo lienzo en el que se proyectaban las sombras. Sólo en las zonas que no estaban expuestas directamente a la luz procedente de los proyectores era visible la proyección. De esta manera, en la misma sombra se encontraban personas desconocidas, que habían sido registradas anteriormente en otros lugares y que ahora aparecían sobre el lienzo como "proyecciones de sombras" (Lieser, 2010: 201-204). 
En Body Movies se posibilitaría expresar situaciones polisémicas y analógicas, abriendo así nuestra capacidad sensitiva a todo tipo de experiencias, en este caso la sensación que tendría un factor subjetivo, intervendría en el proceso artístico y en el disfrute de la obra. C. G. Jung explica cómo junto al objeto percibido sensorialmente estaría el individuo que tendría la sensación y que aportaría al estímulo objetivo su disposición subjetiva. Este autor define la "sensación" como la percepción mediante una función sensorial consciente y la "intuición" como una percepción por la vía de lo inconsciente (Jung, 1994b: 619). Estas funciones se opondrían a las funciones racionales como el pensar o el sentir, que serían funciones enjuiciadoras y valorativas, ya que cuando se piensa se intentaría llegar al juicio o a la conclusión, y cuando se siente se intentaría llegar a una valoración correcta. Pero la sensación y la intuición serían funciones perceptivas y se propondrían percibir lo que ocurriría sin interpretarlo o valorarlo.

\section{Fusión entre arte y tecnología en las manifestaciones artísticas de la urbe.}

Los principales avances científicos y tecnológicos han influido en el arte del siglo XX, adoptando los artistas los nuevos soportes técnicos, como la informática como medios de comunicación y de expresión creativa, haciendo posible que el mundo del arte en la ciudad se adentre en nuevos sistemas de información y comunicación electrónicos con el fin de explorar un espacio digital completamente inédito.

La fusión entre arte y tecnología llega a un punto culminante con la compañía ART-COM fundada en 1988 con sede en Berlín, estando compuesta por un grupo de creadores, científicos, artistas y tecnólogos que realizaron una instalación interactiva llamada Duality, en un complejo de edificios de nueva construcción en Tokio. En este complejo habría un lago artificial bordeado por un camino, donde ART-COM instaló una superficie LED (Light-Emittind Diode, diodos emisores de luz) cuyas dimensiones serían de seis por seis metros, cubierta por un vidrio opalino. Esta instalación interactiva mostraría procesos de la naturaleza y del mundo fenoménico, representados de manera simbólica. Los transeúntes al pisar la superficie, activarían ondas de luz concéntricas que crearían la misma ilusión óptica de una piedra cuando se lanza a un lago; una vez que estas ondas de luz alcanzarían el lago, los impulsos se transferirían a un nuevo medio y las ondas se transformarían en movimientos en el 
agua, representando de esta manera el arquetipo de los contrarios como líquido-sólido, real-virtual, ondas de luz-ondas en el agua.

R. Lawlor analiza la forma en que la consciencia humana poseería la capacidad de percibir la transparencia entre las relaciones absolutas y permanentes, contenidas en las formas insustanciales de un orden geométrico, y las formas transitorias y cambiantes de nuestro mundo real. El contenido de nuestra experiencia procedería de una arquitectura geométrica inmaterial y abstracta que estaría compuesta de ondas armónicas de energía, nodos de relaciones y formas melódicas que brotarían del reino eterno de la proporción geométrica. Así podemos ver como la totalidad del universo desde la gravedad, el electromagnetismo, la luz, el calor o la materia, estaría compuesta por vibraciones, percibidas por nosotros como fenómenos de ondas:

Las ondas son puros patrones temporales, es decir, configuraciones dinámicas compuestas de amplitud, intervalo y frecuencia, y sólo pueden ser definidas y entendidas por nosotros a través del número. Así, todo nuestro universo es reducible al número. Todo cuerpo vivo vibra físicamente, toda la materia elemental o inanimada vibra molecular o atómicamente, y todo cuerpo vibrante emite un sonido. El estudio del sonido, tal y como lo intuyeron los antiguos proporciona una clave para la comprensión del universo. (Lawlor, 1993: 12-13)

R. Lawlor señala que el enfoque de la teoría moderna de los campos de fuerzas y de la mecánica de las ondas corresponde a la visión antigua geométrica-armónica del orden universal como configuración de esquemas de ondas entretejidas, citando a Bertrand Russel que decía: "Lo que percibimos como distintas calidades de materia, son en realidad diferencias en su periodicidad" (Lawlor, 1993: 4).

C. G. Jung señala como hoy en día se sabe que tanto la luz como la materia se comportarían como partículas separadas, pero también se pueden comportar como ondas, de manera que este resultado paradójico habría hecho necesario, según este autor, que en el plano de las magnitudes de orden atómico se llegara a renunciar a la descripción casual de la naturaleza en el continuo espacio-tiempo al que estaríamos acostumbrados:

La descripción casual fue remplazada por campos probabilísticos irrepresentables en espacios pluridimensionales. Tales campos representan el es- 
tado actual de nuestro conocimiento. Este esquema abstracto de explicación se basa en un concepto de la realidad que toma en cuenta los efectos constitutivamente inevitables del observador sobre el sistema que se observa. De este modo la realidad pierde en parte su carácter objetivo y la imagen física del mundo debe incluir un factor subjetivo inseparable (Jung, 1994a: 176).

Estos descubrimientos científicos están llamando la atención del mundo del arte, donde se está intentando fusionar los últimos descubrimientos de nuestra naturaleza con las nuevas tecnologías. Creadores como Carsten Nicolai partirían de un medio sensitivo que intentaría transcender nuestras percepciones ordinarias, mediante una obra que enlazaría nuestra naturaleza física y nuestra consciencia. En 2006 realizará una instalación interactiva de vidrio, aluminio, acero y diversos materiales, que grabaría frecuencias electromagnéticas del entorno como teléfonos móviles, radios u ordenadores portátiles. Todos estos datos se transformarían en una señal de audio y controlarían la situación luminosa dentro de una escultura situada en el exterior, haciéndose así perceptible lo que sería invisible para el observador. Este artista se movería tanto en grandes exposiciones de la escena artística como en el ámbito de la música electrónica, en su página web describe así su obra:

Como artista visual, Nicolai intenta superar la separación de las percepciones sensitivas de las personas, haciendo igualmente perceptibles para la vista y el oído fenómenos científicos como tonos y frecuencias de luz (Lieser, 2010: 204).

El bioquímico Rupert Sheldrake, doctor en Ciencias Naturales por la Universidad de Cambridge y Research Fellow de la Royal Society de Inglaterra afirma que nuestra mente no estaría centrada sólo en nuestros cuerpos o cerebros, sino que se extenderían más allá de éstos, realizándose esta extensión a través de "campos mentales" que este autor sitúa tanto en el interior de nuestro cerebro como fuera de él:

Los campos magnéticos, como los electrónicos y los gravitatorios son invisibles aunque capaces de provocar efectos a distancia. Del mismo modo, los campos de nuestras mentes no están confinados en el interior de nuestros cráneos, sino que se extienden más allá de ellos. Yo sugiero que nuestra actividad mental depende de campos invisibles que pueden provocar efectos a distancia (cit. Bautista, 2015: 262). 
K. Korotkov señala como a finales del siglo XX el campo biológico se asociaría fuertemente con el campo electromagnético además de producirse durante décadas discusiones muy activas sobre la posible existencia de otros campos, como los campos de torsión de Anatoly Akimov y su equipo, que a pesar de ser una de las ideas más avanzadas en su momento, no pudieron convencer a la comunidad científica de su importancia. Este investigador afirmaba que alrededor de cualquier objeto biológico emergería durante su existencia un cuadro complicado de campos físicos, cuya distribución en el espacio y cambio en el tiempo proporcionaría la información biológica importante que se podría utilizar, en particular en el diagnostico médico. Esta idea se basaba en que el campo electromagnético se generaría mediante el movimiento de cargas eléctricas:

Una variedad de procesos eléctricos está en marcha en el cuerpo de forma continua, desde el nivel de las células al nivel de los sistemas y órganos individuales. El campo electromagnético está asociado con cada uno de estos procesos (Korotkov, 2015: 207).

Mariko Mori experimentará con imágenes digitales y realidad virtual representando una fusión entre el budismo y el sintoísmo en obras como Wave UFO de 1999-2002, donde aparecía una gigantesca nave espacial instalada en el atrio acristalado de un edificio de Manhattan. Los espectadores que penetraban en la nave se conectaban a unos electrodos que monitoreaban sus ondas cerebrales, generando un espectáculo luminoso que respondería en parte a la actividad cerebral del espectador y en parte a una animación gráfica programada donde la artista pretende transportar al público a nuevos estados de consciencia e iluminación espiritual.

M. Kaku dice que puede llegar un día en que registremos minuciosamente todas las señales que atraviesan el hipocampo, el tálamo y el resto del sistema límbico pudiendo generar una grabación detallada de ellas. Se podría insertar esta grabación en nuestro cerebro, siendo capaces de volver a experimentar la totalidad de lo que otro individuo habría vivido. Según Kaku puede que entre mediados de siglo y finales, se pueda grabar la totalidad de los estímulos que llegan al cerebro, para ello haría falta conectarse directamente a los datos sensoriales que suben por la médula espinal hacía el tálamo. Recoge la afirmación del doctor Nicolelis cuando escribe: 
No es inconcebible que nuestra progenie pueda reunir las habilidades, tecnología y ética necesarias para implantar una brain-net, el medio a través del cual miles de millones de seres humanos establecerían contactos consensuados, temporales y directos entre sí exclusivamente a través del pensamiento. Ni yo ni nadie puede actualmente imaginar el aspecto o el funcionamiento de tan colosal consciencia colectiva (Kaku, 2014: 131).

Con estas nuevas técnicas, los artistas comunicarían y expresarían de otra forma sus vivencias, permitiendo al público visionar las imágenes y los pensamientos generados por la mente, e incluso el público podría también manifestar de este modo sus emociones y compartirlas con otras personas, con estos recursos se podrían expresar experiencias interiores del artista implicando al público en su propio estado de ánimo.

Mediante escáneres de imagen por resonancia magnética se puede descomponer las distintas estructuras que intervendrían en cada nivel de nuestra consciencia. Para M. Kaku el flujo de consciencia al que llama de "nivel I" sería en gran medida la interacción entre la corteza prefrontal y el tálamo, poniendo como ejemplo que si un individuo paseara por un parque seríamos conscientes de

... los olores de las plantas, la sensación de una brisa ligera, los estímulos visuales de la luz, etcétera. Nuestros sentidos envían señales a la columna vertebral, al tronco encefálico y después al tálamo, que opera como una estación repetidora y clasifica los estímulos antes de mandarlos a las distintas cortezas cerebrales (Kaku, 2014: 84).

La consciencia de "nivel I" utilizaría las sensaciones para crear un modelo de nuestra situación física en el espacio, pero también existiría la de "nivel II" que produciría un modelo del lugar que ocupamos en la sociedad, que no sólo se limitaría a reconocer a otras personas, sino que el cerebro poseería la misteriosa capacidad de adivinar en qué están pensando. El doctor David Premack, de la Universidad de Pennsylvania la denominó "teoría de la mente" y consistiría en la capacidad de deducir los pensamientos de los demás. A esta teoría se llegó en 1996 con el descubrimiento de las "neuronas espejo" por los doctores Giacomo Rizzolatty, Leonardo Fogassi y Vittorio Gallese. Según M. Kaku estas neuronas se activarían cuando realizamos determinadas tareas y cuando vemos a otra persona llevando a cabo esas mismas acciones. Estas neuronas serían fundamentales para la imitación y para la empatía, ya 
que no sólo nos permitirían copiar acciones complejas que otros llevarían a cabo, sino también experimentar las emociones que estos individuos sentirían, teniendo una gran importancia en nuestra evolución, al facilitar la cooperación para mantener unida la sociedad. Estas neuronas espejo se activarían tanto por emociones como por actos físicos, activándose igualmente tanto si sentimos determinada emoción como si pensamos que otra persona la está sintiendo. El doctor V. S. Ramachandran cree que fueron fundamentales para hacer posible nuestra autoconsciencia concluyendo:

Predigo que las neuronas espejo harán por la psicología lo que el ADN hizo por la biología: servirán como marco unificador y contribuirán a explicar todo un abanico de capacidades mentales que hasta ahora eran misteriosas e inasequibles a los experimentos (Kaku 2014: 87).

Estas neuronas espejo se descubrieron en la corteza prefrontal humana, aunque algunos críticos dicen que es posible que estas funciones también sean comunes a muchas neuronas y que no existiría una única clase de neuronas dedicada a esta función. Además poseeríamos una consciencia de un nivel más elevado, a la que denomina la consciencia de "nivel III", en la que partiendo de nuestro modelo del mundo realizaría simulaciones hacia el futuro:

En la simulación del futuro, el núcleo de la consciencia del nivel III, interviene la corteza dorsolateral prefrontal, el CEO del cerebro, con la participación del centro del placer y la corteza orbifrontal (que actúa para controlar los impulsos). Esto se parece, aproximadamente, a la descripción que propuso Freud de la lucha entre consciencia y deseo. El proceso de simulación propiamente dicho se produce cuando la corteza prefrontal accede a los recuerdos para hacerse una idea aproximada de los eventos futuros (Kaku, 2014: 89).

La evolución cultural en la especie humana, según Thibault, tomó el relevo de la evolución biológica. La evolución cultural puede provocar una evolución biológica, basándose en que el individuo sería capaz de modificar su medio de desarrollo de tal forma que las modificaciones del medio ambiente repercutirían sobre sus bases neurofisiológicas y, por lo tanto, sobre las del comportamiento. El desarrollo del cerebro sería mayor en la especie humana que en cualquier otra especie de primates:

La aparición del neocórtex (lóbulos órbito-frontales) condujo a una "corticalización" creciente de los comportamientos en general y del comporta- 
miento sexual en particular. Eso complica singularmente los problemas de relación entre los sexos y los individuos, conlleva posibilidades de invención y de cambio y, en consecuencia, una gran variedad de comportamientos sexuales y familiares, a la vez en el espacio -según las culturas- y en el tiempo -en el curso de la historia de cada una de ellas. (Thibault, 1979: 33).

La ciudad puede ofrecer una comunicación a otros niveles a través del arte interactivo y las nuevas tecnologías que tendría que ver con la totalidad de la condición física, mental y psicológica del individuo que percibe; siendo posible volverse consciente de otros campos vibratorios no percibidos por nuestros sentidos y que por medio de la experiencia artística se puede acceder a ellos.

Las fachadas mediáticas de las ciudades se relacionarían con un medio de representación que lo haría visible, entre las que se encontrarían aquellas que tomarían datos del entorno y los evaluaría para crear nuevos datos y representarlos, como la fachada de Zeilgalerie de Frankfurt/Main que procesaría datos meteorológicos y los haría visibles. K. Korotkov señala como el siglo XX se caracterizó por la gran revolución en la física, la toma de conciencia del carácter limitado del modelo newtoniano-cartesiano, además del enfoque mecanicista del universo, todas estas ideas habrían mantenido su poder gracias a los procesos mentales y el papel de la consciencia en el mundo:

Las nuevas ideas se están formando poco a poco, acumulando datos e ideas, con el fin de que en algún momento, por un impulso, se traduzcan en la conciencia pública como una nueva manera de pensar. Este punto se acerca cada vez más. Su aproximación depende de nosotros (Korotkov, 2015: 219).

Los artistas mediante la transformación de los edificios crearían símbolos de gran alcance público, constituyendo éstos una manifestación psíquica de nuestro ser, al dotar a los edificios de una gran importancia psicológica a través de la luz. La ciudad se convierte así en una nueva expresión de estas nuevas manifestaciones artísticas, mediante símbolos lumínicos que combinan con el color, como vemos en la obra de Toyo Ito, que en 1986 realizará una intervención en una torre de ventilación y suministros de agua a la que llama Torre de los Vientos, situada en la plaza de la terminal de autobuses de la estación de Yokohama (Japón). Una vez rehabilitada, rodeó la torre con un recubrimiento perforado en forma de cilindro elíptico que por la noche quedaría iluminado:

... la superficie acrílica del cilindro pierde corporeidad, su solidez se hace transparente, revelando distintas capas de anillos y puntos de luz que 
constituyen el repertorio luminoso del que se vale un sistema informático para transformar las informaciones ambientales -ruido de la plaza circundante y de su tráfico rodado, velocidad, y dirección del viento...- en una impresionante "traducción" lumínica (Rambla, 2008: 759-760).

Esta intervención de Toyo Ito no sería una idea nueva, Nicolás Schöffer, húngaro residente en París, ya realizó en 1960 la obra titulada Esculturas espaciodinámicas, siendo su objetivo la creación de una ciudad cibernética que reaccionara a las diferentes horas, temperaturas y condiciones climáticas del día con luz y movimiento. En esta misma línea la Sede de la red de compañías afiliadas de gas de Leipzig, proyectada por Becker Gewers Kühn \& Kühn, instalaría un sistema de energía inteligente que reaccionaría automáticamente a los factores externos meteorológicos, sobre todo a la luz. El artista James Turrell diseñó un programa lumínico que como dice W. Rambla tendría el fin:

...de que el edificio manifestara en su <piel> el paso o variación que experimenta al ir menguado la luz solar y caer la noche. Así, la fachada de vidrio empieza a brillar al anochecer mediante una serie de tonalidades rosa, naranja y rojo- características de la puesta del sol en su camino hacia la nocturnidad (Rambla, 2008: 761).

Las fachadas de las ciudades se convierten en grandes lienzos o esculturas, donde la luz recrearía una ilusión óptica que tendría que ver con nuestra realidad circundante llena de información relacionada con el ambiente, la atmósfera, el sonido, el color o el bullicio de la ciudad, que estarían incidiendo en sus habitantes de manera muy significativa. A. Daniélou afirma que el misterioso intercambio entre vibraciones y formas, se basarían en las grandes culturas espirituales del pasado. En su obra Traité de musicologie comparée explica cómo desde los átomos hasta el universo, cada uno de los movimientos cósmicos poseería un tiempo, un ritmo, una periodicidad que podría compararse a la vibración y por tanto a un sonido que expresaría su naturaleza:

No todas las vibraciones son perceptibles a nuestros oídos, pero las relaciones entre vibraciones pueden compararse a las relaciones entre frecuencias audibles. Todos los átomos pueden considerarse así como las formas de una energía que se expresa en un ritmo, y todas las sustancias están caracterizadas por una relación particular de ritmos que se puede representar mediante una relación de sonidos. Es gracias a esta similitud entre, por una parte, las relaciones de los sonidos, y por otra, las formas y las sustancias de la naturaleza como se hacen posibles el lenguaje y la música (Lawlor, 1993: 89). 
F. Wilczek dice que nuestra imaginación nos revelaría información sobre lo que ocurriría en el espacio, mientras que el color nos diría lo que ocurre en el tiempo, explicando como el color nos daría "información sobre las variaciones rápidas de los campos electromagnéticos que llegan a nuestros ojos" (Wilczek, 2016: 159) El espacio de la información del color sería "infinito-dimensional" (ídem: 160), lo que ocurre es que percibiríamos como color, solo una superficie tridimensional, sobre la que se proyectarían "esas infinitas dimensiones" (ídem).

\section{La luz y la naturaleza como elemento de comunicación de masas en el arte interactivo de la ciudad.}

El arte y las nuevas tecnologías estarían buscando con los actuales medios materiales, nuevas vías más sutiles de comunicación e interacción entre los individuos y el entorno, siendo la luz un elemento clave de comunicación de masas. Thomas Wilfred ya realizó en la década de 1920, una máquina llamada "Clavilux" semejante a un teclado que proyectaba haces de luz sobre los rascacielos de Nueva York. Los artistas actuales, al igual que Thomas Wilfred, se servirán de las fachadas de los edificios para presentar visualmente distintos contenidos, mediante una fuente de luz que cree sombras en aquellas, produciendo diversas sensaciones en los viandantes.

C. G. Jung señala como los atributos lumínicos e ígneos describirían la intensidad de la tonalidad afectiva, siendo expresiones de la energía psíquica que se manifestaría como libido, poniendo de ejemplo que cuando se adora a dios, al sol o al fuego, se adoraría la intensidad o la fuerza, o lo que sería lo mismo se adoraría al fenómeno de la energía anímica de la libido:

Toda fuerza y en general todo fenómeno es cierta forma de energía. La forma es imagen y modo de manifestación. Expresa dos clases de cosas: en primer lugar la energía que en ella adquiere forma, y en segundo lugar el medio en que aparece la energía. Puede afirmarse, por una parte, que la energía crea su propia imagen, y, por otra, que el carácter del medio obliga a la energía a adoptar una forma determinada. Uno derivará del sol la idea de dios; otro, por el contrario, opinará que es la numinosidad condicionada por la tonalidad afectiva lo que determina que se reconozca significación divina al sol (Jung, 1993b: 109-110).

El paisaje urbanístico se vería transformado por estos nuevos enfoques donde el color, el sonido, las formas y la luz transformarían de manera sus- 
tancial los edificios y la percepción de éstos por los viandantes. T. Edler piensa que este fenómeno hace que la arquitectura pierda su derecho a decidir el aspecto externo que deben tener los edificios, los asentamientos y los sistemas de infraestructura, surgiendo nuevas posibilidades para los participantes, llegando a la conclusión de que la arquitectura se habría quedado atrasada desde hace 40 años en su propia exigencia de concebir y crear edificios y ciudades como sistemas complejos y dinámicos. Para este autor la contextualización de nuevas partes del edificio y sistemas se relacionaría con la aplicación de métodos que descubran la forma y su análisis, tales como normas, tamaño, abstracción, lenguaje formal, composición material, colores, velocidad, uso, etc. T. Edler cree que de esta manera:

...los ámbitos formales elementales se abrirán gradualmente, por lo general de modo llamativo, creando posiciones contrarias en lo referente al concepto de una utilización tecnológicamente determinada. La inclinación o el rechazo de una determinada tecnología, se convertirá en una decisión formal artística, dejando de considerarse una decisión técnicamente planificable. La utilización de técnicas anticuadas, como en las instalaciones con fluorescentes (BIX, SPOTS, Crystal Mesh), se produjo de forma premeditada, entre otros motivos para garantizar un envejecimiento sincronizado de las instalaciones (cit. Lieser, 2010: 248).

Estas fachadas mediáticas interactivas pueden convertirse en un elemento de transmisión donde tendría lugar una comunicación entre dos posiciones distintas, utilizando la estructura exterior de un edificio, que se transforma en un vehículo de información cambiante, al mismo tiempo que permitiría al público tener una influencia directa sobre la imagen representada. Entre este tipo de fachadas destacaría Tousch (Tacto) de la torre Dexia en Bruselas, que fue intervenida por el grupo artístico LAb [au] -Laboratory for Architecture and urbanism- integrado por Manuel Abendroth (Alemania), Jeróme Decock, Alexandre Plennevaux y Els Vermang oriundos de Bélgica. Estos creadores utilizaron todo el edificio como una instalación de luz, empleando distintas composiciones abstractas basadas en diversos software, y para llevar a cabo su proyecto colocaron en las 4.200 ventanas del edificio una base de pantalla LED con los colores primarios rojo-verde-azul.

Este proyecto de la torre Dexia permitía a los participantes a través del tacto y de los movimientos sobre la pantalla táctil instalada en una estación si- 
tuada en la base del edificio, dirigir el proceso de la instalación de luz del rascacielos. Además en el edificio colindante el público podía utilizar una cámara mediante una pantalla táctil, creando una composición luminosa en la torre Dexia, que se ha convertido en un nuevo símbolo de la ciudad.

Este grupo artístico ha realizado también un trabajo llamado Chrono, donde los colores serán fundamentales, mostrando de forma esquemática la hora en la torre mediante los colores primarios de la luz. Como vemos estos artistas relacionarían los colores con diferentes horas del día, como hiciera Pitágoras, al formular la teoría de las esferas y crear las bases de la lectura y transmisión musical, ofreciendo "al mundo la sincronía entre chakras y colores, entre colores y notas musicales y horas del día y de la noche compatibles con tipos de danza, músicas y cantos"' (Pérez de Carrera, 2004: 197).

Los artistas han encontrado en las fachadas mediáticas, un soporte público de exposición y de experimentación, donde el arquetipo de la planta aparecerá de forma numerosa llevando esta temática a las fachadas de los edificios, para ello han creado sistemas interactivos que buscan nuevas alternativas para exponer sus obras. Christa Sommerer y Laurent Mignonneau realizaron en 2006 una interface artística para un espacio público en la ciudad de Braunschweig titulada Planta del conocimiento, donde los viandantes pueden ver en pantallas situadas en las fachadas del edificio una serie de imágenes donde aparecen plantas virtuales que crecen, además de imágenes que cambian cuando el espectador se mueve. Christa Sommerer y Laurent Mignonneau describen así su obra:

En cuanto los viandantes se acercaran al edificio de cristal, los sensores notificarían su presencia y su distancia que los separaba de la pantalla (en un radio de distancia entre 0,1 y 1,5 metros). Además, desarrollamos un programa especial para la "Planta del conocimiento", que convertía la proximidad y la velocidad del viandante en parámetros de crecimiento para las plantas virtuales. Un ejemplo: si la persona se detenía, aparecía en la pantalla una determinada planta virtual; si el transeúnte caminaba despacio, el programa se ocupaba de que la planta siguiera a la persona a lo largo de diversas pantallas. Para que crecieran nuevas plantas, el transeúnte debía alejarse de la pantalla y volver a acercarse de nuevo a una distancia inferior a 1,50 metros. Todos los datos o plantas generados por el "usuario" formaban un paisaje de imágenes en constante crecimiento (cit. Lieser, 2010: 244). 
ART-COM realizó la fachada mediática de Vattenfall Europe AG en Berlín; para ello utilizaron cañones de luz que proyectarían en la fachada una serie de ventanas de forma vertical y horizontal. El fin de estas superficies-instalación era crear varios trabajos generativos, donde insertaron la obra de Marius Watz titulada Neon Organic de 2005, cuya instalación se desarrollaría sobre diferentes ventanas de forma separada y de una pasada, mostrando una composición abstracta, donde aparecen raíces de plantas polícromas que van evolucionando hasta romperse y convertirse en bolas que se dispersan en todas direcciones.

R. Lawlor señala como el enfoque de la vida o de la evolución sería un momento transformador que existiría realmente, donde los mundos fenoménicos serían un reflejo transitorio que constituirían el pasado y el futuro de una eternidad siempre presente, entendiendo las formas naturales como símbolos que revelarían los principios arquetípicos metafísicos que guiarían y controlarían la evolución universal, poniendo de ejemplo la raíz de las plantas que crecería mediante la constante división de su forma cuadrada: "Las células de la raíz son una poderosa metáfora del principio de integración y transformación" (Lawlor, 1993: 30).

La investigación sobre botánica es aplicada hoy en día a la experimentación arquitectónica digital, planteando la posibilidad de una nueva generación de estructuras, cuyo desarrollo se basaría en las propiedades de un organismo vegetal. La planta simbolizaría la energía solar condensada y manifestada, ya que las plantas captarían las fuerzas ígneas de la tierra y recibirían la energía solar acumulada en potencia, así el proceso de fotosíntesis se representaría simbólicamente en el rosetón de las catedrales góticas que trasforman la luz en un espectro de colores:

Las plantas simbolizarían también la manifestación de la energía en sus formas diversas, como la descomposición del espectro solar en colores variados. En cuanto que manifestación de la vida, son inseparables del agua, como del sol (Chevalier y Gheerbrant, 1999: 665).

El mexicano Miguel Chevalier trataría de expresar las relaciones del ser humano con el mundo vegetal, en su instalación Sur-Natures presentada en 2007 en los Campos Elíseos. En esta obra se podía ver una proyección interactiva que reproduciría un contenido prefabricado, consistente en imágenes de plantas que crecían y cambiaban su aspecto en función de las señales que re- 
gistraban los movimientos de los transeúntes. Esta instalación de gran riqueza cromática, reproduciría plantas y estructuras orgánicas donde capturaría estructuras botánicas que transformaría mediante tonos que nos recuerda los últimos avances en la captación de la energía de los seres vivos vegetales realizadas por K. Korotkov, que afirmaría como la consciencia humana puede influir en los procesos físicos de nuestro mundo, poniendo de ejemplo al biólogo indio G. Boshe, que en la década de 1920 investigaría el efecto del pensamiento sobre la actividad vital de las plantas. Esta teoría muestra que el pensamiento humano sería energía, que puede influir en todo nuestro entorno, incluyendo las plantas, los animales y el ser humano:

De acuerdo con la ley de conservación de la energía, el pensamiento es indestructible. La humanidad está constantemente pensando en el proceso de su actividad, haciendo su contribución a la energética de la Tierra. Y esto significa que cada persona debería ser muy responsable de la calidad de sus pensamientos (Korotkov, 2015: 136).

En este mismo sentido E. Pérez de Carrera señala cómo en el caminar cotidiano del individuo por la vida todo se alteraría, de forma que inconscientemente estaríamos modificando el orden de las cosas, sin calibrar el nivel de consecuencia que tendría cada una de nuestras acciones, por muy insignificante que nos parezcan: "Todo se desordena en cada instante, cada mirada recoloca el mundo, cada pisada mueve todos los ritmos telúricos, cada respiración redime una espera y abre la marcha a un nuevo peregrino" (Pérez de Carrera, 2004: 221).

Nuestra mente puede influir directamente en el mundo que nos rodea, siendo nuestra consciencia una energía que tendría relación con la materia y la información. C. G. Jung considera que la realidad estaría más allá de nuestros límites corporales:

La conciencia percipiente se ha mostrado capaz de evolución en alto grado y ha construido instrumentos con cuya ayuda la percepción de la vista y del oído se ha ampliado grandemente. Con ello se extendió en un grado inaudito el mundo fenoménico postulado como real y también el mundo subjetivo de la conciencia. La existencia de esta notable correlación entre conciencia y mundo fenoménico, entre la percepción subjetiva y los procesos reales objetivos, o más bien entre la percepción y los efectos energéticos de esos procesos no necesita ser demostrada detalladamente (Jung, 1994a: 175). 
M. Bautista Pérez, refiriéndose a nuestra biología, cree que en un futuro se podían producir descubrimientos que amplíen la idea que tenemos de nuestra configuración biológica, rompiéndose así con los límites materiales que actualmente tenemos de ésta; incluso no llega a descartar el descubrimiento de una realidad energético-material integrada e interconectada con nuestra configuración biológica:

¿Y si esa hipotética realidad energético-material no se circunscribiese exclusivamente al ámbito actualmente conocido de nuestro cuerpo y operase más allá de nuestra piel? ¿Por qué creemos que la piel define los confines de nuestra realidad física como seres humanos? La respuesta típica es que hasta ahora no hemos visto nada que nos haga suponer otra cosa. Pero llegados a este punto, conviene tomar nota de lo poco que somos capaces de ver en relación con lo que sabemos que existe (Bautista Pérez, 2015: 268).

Cree que tal vez estemos reduciendo demasiado nuestra idea que tenemos de la realidad, al limitarla a una dualidad mente-cerebro o incluso menteorganismo, llegando a la conclusión de que si nuestros sentidos ayudados incluso por la tecnología actual, no alcanzan a percibir toda la realidad material y energética de nuestro entorno, tampoco estaremos percibiendo el alcance total de nuestra realidad material y energética como individuos:

Bien podía suceder que, al margen de lo que sea y hasta donde llegue eso que llamamos mente o eso que llamamos cuerpo físico, haya otros ámbitos de nuestra realidad que no sean ni lo uno y lo otro. O por lo menos que no lo sean de acuerdo con la imagen que nos hemos construido sobre ambos (Bautista Pérez, 2015: 269).

Para este autor la realidad que nos configuraría no sólo sería de un plano físico y otro mental, sino que podría haber otros, que estuvieran más o menos interconectados entre sí, o incluso plenamente integradas pero que fuesen de naturaleza relativamente diferentes a las que conoceríamos (Bautista Pérez, 2015: 270). Pone como ejemplo las últimas investigaciones sobre el universo, así en 1970 se detectaron determinadas alteraciones en los campos gravitatorios, confirmando la existencia de la materia oscura, llegando los astrónomos a la conclusión de que en el universo habría cuatro veces más de materia oscura que no se sabe qué es, frente a la de materia conocida:

Para complicar aún más las cosas, en 1998 se llegó a la conclusión de que en el universo debía haber algo que explicara determinados efectos que se ve- 
nían observando en relación sobre todo con su expansión. A ese algo los astrónomos lo bautizaron como energía oscura y, por supuesto, tampoco se sabe qué es. Pues bien, actualmente se cree que del conjunto de materia y energía que hay en el universo, en torno al 74\% es esa energía oscura, el 21\% es materia oscura y solo un 5\% restante estaría compuesto por la materia conocida. Es decir, en los últimos 40 años hemos pasado de creer que el 95\% del universo estaba vacío, a admitir que está lleno y, además, por un tipo de materia y de energía completamente desconocidos (Bautista, 2015: 267).

Así, afirmará que en la medida en que la ciencia avance en el conocimiento de esta materia oscura y de la energía oscura, podría ir descubriendo diversas realidades e incluso que todas esas realidades o algunas estuviesen jugando papeles de gran importancia en nuestro funcionamiento como seres humanos e incluso tendrían más importancia que nuestra realidad biológica, tal como la conocemos. Es evidente que estamos muy lejos de identificar los mecanismos que producirían no sólo nuestra consciencia, sino también "...la inteligencia, el pensamiento, la creatividad o la sensación de identidad, por citar sólo algunas de las características que nos hacen sentirnos humanos" (Bautista Pérez, 2015: 272).

Llamará la atención sobre las casi desconocidas relaciones tienen la inteligencia, el pensamiento reflexivo o la creatividad con los aspectos más visibles de nuestra anatomía y morfología. Nuestro entorno sería un conglomerado de "fuerzas" e influencias que pueden ser conocidas o no, e incluso podemos intuirlas, citando a Hermann J. Muller que recibió el Premio Nobel en 1946, y que fue capaz de provocar:

...importantes mutaciones genéticas en moscas que generaban cambios espectaculares en sus organismos sin más que someterlas a ciertas dosis de rayos $X$. Posteriormente se vio, en sucesivos experimentos, que esto también sucedía en otros animales y plantas. Se concluyó que, dado que recibimos muchos tipos de radiaciones procedentes del cosmos e, incluso, de la corteza y del interior de la Tierra, ésta podía ser una de las causas que provocan las mutaciones que experimentamos en nuestra genética (Bautista Pérez, 2015: 406-407).

La física cuántica está logrando nuevos conocimientos relacionados con el misterio de nuestra consciencia, que podrían liberar al hombre de su encadenamiento a los aparatos que la tecnología ha ido construyendo desde el siglo 
XX. D. Kerckhove afirma que ya se estaría produciendo un cambio de paradigma que dependerá de la tercera fase de la electricidad, la fase cuántica. Según este autor ya se habría sobrepasado las fases analógica y digital, y el ordenador cuántico estaría ya en una etapa más avanzada:

Es probable que retrocedamos a un nuevo tipo de cosmología cuántica en la que el ser humano se sitúe otra vez en el centro del universo, pero no como centro de materia física, sino simplemente como centro de toda la información que hemos elaborado al respecto (Kerckhove, 2012).

R. Lawlor señala como en nuestra época habría una convergencia entre la nueva ciencia biológica basada en la cibernética y en la teoría de la información, y la doctrina mística del antropocosmos. Ya que podemos encontrarnos con el universo en evolución, no sólo a nuestro alrededor, sino también dentro de nosotros mismos mediante nuestras capacidades sensoriales. Para este autor nuestra organización corporal en cinco o más niveles perceptivos distintos, habría poco en común entre el espacio visual, el espacio auditivo y el espacio táctil, existiendo todavía menos conexión entre los distintos niveles de conciencia del espacio psicológico:

Por tanto, nuestros cerebros y cuerpos dan necesariamente forma a todas nuestras percepciones, y éstas a su vez han sido formadas por las mismas energías visibles e invisibles que han dado forma a todo aquello que se puede percibir. Cuerpo, mente, y universo deben formar una identidad formativa y paralela (Lawlor, 1993: 92).

La mecánica cuántica ha sido un campo capaz hasta ahora de hacer posible los láseres, los escáneres de imagen por resonancia magnética, la radio, la televisión, la electrónica moderna, el GPS o las telecomunicaciones, pero podemos también pensar que si el ser humano ha sido capaz de inventar todo este tipo de tecnología, es porque todo esto existe dentro de nosotros y algún día seremos capaces de utilizar todas estas potencialidades sin la necesidad de emplear máquinas que nos sustituyan. La especulación mental acerca de la realidad constituye una barreara para la experiencia inmediata e íntima de la misma, por lo que el artista tendrá que dejar en un segundo lugar a la razón y guiarse por la intuición en el acto creativo. 


\section{Conclusiones.}

El arte digital en el espacio público, las fachadas mediáticas y el arte interactivo de las ciudades se habrían convertido en un canalizador de información que nos ayudaría a descubrir al artista y a su obra, y no sólo la forma y los elementos de dicha obra, sino el espíritu del que brota y las impresiones que su impacto crea en la mente del público, produciéndose así en la ciudad un momento transformador que existiría realmente, donde el mundo fenoménico puede ser un reflejo de nuestro pasado pero también de nuestro futuro, entendiendo las formas naturales como símbolos que revelarían principios arquetípicos metafísicos universales.

Los principales avances científicos y tecnológicos estarían propiciando nuevos sistemas de comunicación electrónicos que se han fusionado con el arte actual y que habrían ayudado a ampliar nuestro campo de conciencia colectiva de las grandes urbes, donde los artistas y el público comenzarían a tener un papel más activo gracias a la instalación en diversas ciudades de obras interactivas, que permitirían la participación de numerosos espectadores. Estas instalaciones captarían y procesarían señales procedentes del exterior, mostrando el resultado de forma perceptible, de manera que una vez percibidas producirían algún tipo de reacción interactiva en el público, poniendo en marcha su imaginación e intuición, funciones que serían vitales para que el individuo comprenda los símbolos culturales y naturales relacionados con nuestra vida y evolución.

La ciudad del futuro debe ser concebida como un elemento transformador de nuestro pensamiento, al constituir una pieza clave en el desarrollo histórico del ser humano, donde el arte actual de las grandes ciudades puede ser un primer paso hacia esta nueva consciencia, al ser ésta una energía relacionada con la materia y la información, ya que como hemos visto nuestra mente puede influir directamente en el mundo que nos rodea.

\section{Bibliografía.}

BAutista PÉRez, M. (2015). La paradoja de Darwin o el enigma del Homo sapiens, Col. Divulgación Científica, Guadalmazán., Madrid.

Chevalier, J. GHeERbrant, A. (1999), Diccionario de los símbolos. Heder. Barcelona. 
JUNG, C. G. (1993a), Las relaciones entre el yo y el inconsciente. Col. Biblioteca de Psicología Profunda no 114, Paidós. Barcelona.

(1993b) Símbolos de transformación. Col. Biblioteca de Psicología Profunda $\mathrm{n}^{\mathrm{o}}$ 7, Paidós. Barcelona.

(1994a), Arquetipos e inconsciente colectivo. Col. Biblioteca de Psicología Profunda $\mathrm{n}^{\mathrm{O}}$ 14, Paidós. Barcelona.

(1994b). Tipos psicológicos. Edhasa. Barcelona.

KAKU, K. (2014), El futuro de nuestra mente. El reto científico para entender, mejorar, y fortalecer nuestra mente. Debate. Barcelona.

KANDEL, E. R. (2013). La era del inconsciente. La exploración del inconsciente en el arte, la mente y el cerebro. Paidós. Barcelona.

KeRCKHOVE, D. (2012): Entrevista a D. Kerckhove, Las tecnologías reestructuran nuestras mentes. [Consultado el 17 de Octubre de 2014], en http://www. banquete.org/banquete05/visualizacion. php?id=171

KOROTKOV, K. (2015), La energía de la consciencia. Ediciones Obelisco. Barcelona.

LAWLOR, R. (1993), Geometría Sagrada. Debate. Madrid.

LIESER, W. (2010), Arte digital. Nuevos caminos en el arte. Ulmann. Potsdam h. f.

PÉREZ DE CARRERA, E. (2004), 49 Respuestas a la aventura del pensamiento. Tomo I. Fundación Argos. Madrid.

PÉRez de CARrerA, E. (2009). La Educación en la era planetaria. Primer ciclo sobre complejidad y modelo pedagógico. Madrid. (Consultado 4 de Enero de 2015)http://www.tendencias21.net/ciclo/Desde-la-educación-debe-ponerseen-crisis-el-modelo-educativo a29.html.

RAMBLA, W. (2008), Principales itinerarios artísticos en la plástica y arquitectura del siglo XX: una aproximación a la teoría del arte contemporáneo. Col. Universitas, nํㅡㄹ 28. Universitat Jaume I, Castellón de la Plana.

TEILHARD DE CHARDiN, P. (1964), El porvenir del hombre. Taurus. Madrid.

TriBe, M. JANA, R. (1998), Arte y nuevas tecnologías. Taschen, Uta Grosenick. Bonn.

WiLCZEK F. (2016). El mundo como obra de arte. En busca del diseño profundo de la naturaleza. Critica. Barcelona. 